\title{
E-medicine helps diagnosing and classifying underlying causes of stroke
}

\author{
Fabiola Serrano ${ }^{1}$, Pierre-Jean Touboul ${ }^{1}$, Julien Labreuche ${ }^{1}$, Pierre Amarenco ${ }^{1}$ \\ 1. Department of Neurology and Stroke Centre, Bichat University Hospital, Paris, France
}

Background and objective: After an ischemic stroke or a TIA, the presence of underlying potential causes drives the preventive treatment, based on guidelines. ASCOD phenotyping has been designed to determine the most likely potential cause, without neglecting the concomitant presence of other underlying causes less likely or not directly related to the stroke.

Method: we developed an algorithm to automatically phenotype stroke patients in all main causal diseases ( $\mathbf{A}$ : atherosclerosis; S: Small vessel disease; C: Cardiac pathology; O: Other are causes; D: Dissection).
We then developed a smartphone and tablet application available on IOS and Android systems.

Results: ASCOD App is a free application now available online and can be downloaded from specific e-stores (Apple Sore and Google Play Store) in English, French, German, Spanish, Portuguese, Mandarin, Cantonese, Japanese, and Korean languages. After entering patient data, the application generates a report on potential, possible or unrelated underlying causes that helps preventive treatment decision making.

Conclusions. ASCOD app is the first application available at bedside to find out potential causes of stroke and guides preventive treatment.

\begin{tabular}{|c|c|}
\hline 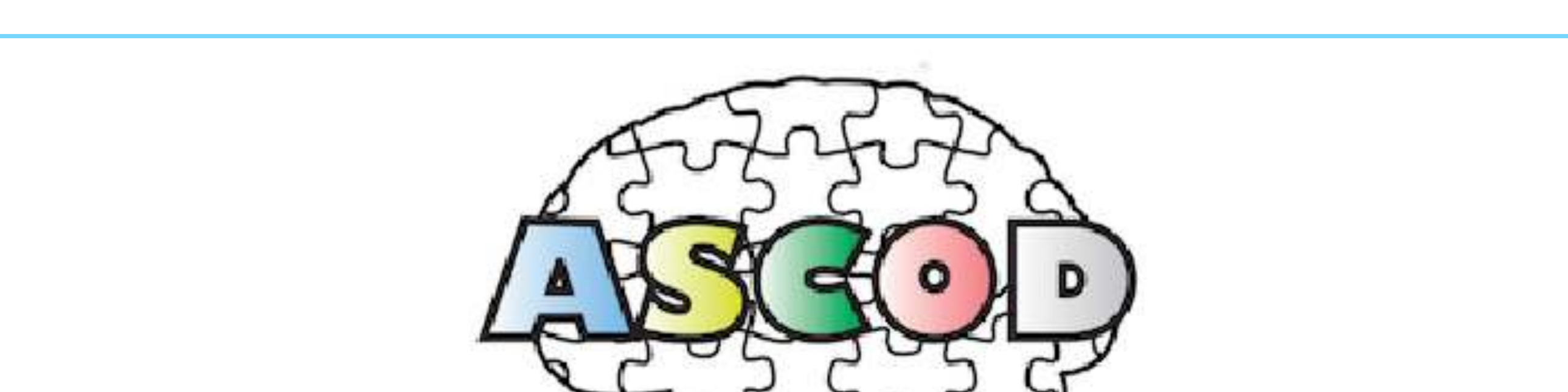 & $\begin{array}{l}\text { A-ATHEROSCLEROSIS } \\
\text { Absence of disease } \\
\text { Insufficient work up to grade this phenotype } \\
\text { Presence of disease }\end{array}$ \\
\hline $\begin{array}{l}\text { After selecting your language, click on the button below to start grading } \\
\text { your patient and get report on her/his cause(s) of ischemic stroke } \\
\text { ASCOD grades ischemic stroke potent causes as : } \\
\text { 1. Definite : causal link is potential }\end{array}$ & $\begin{array}{l}\text { S - SMALL VESSEL DISEASE } \\
\text { Absence of disease } \\
\text { Insufficient work up to grade this phenotype } \\
\text { Presence of disease }\end{array}$ \\
\hline $\begin{array}{l}\text { 2. Possible : causal link is uncertain } \\
\text { 3. Unrelated : pathology is present but causal link is unlikely }\end{array}$ & $\begin{array}{l}\text { C- CARDIAC DISEASE } \\
\text { Absence of disease }\end{array}$ \\
\hline $\begin{array}{l}\text { A 92-year-old woman with a previous history of arterial } \\
\text { hypertension presented to our department with pure motor } \\
\text { hemiparesis, NIHSS }=3 \text {. } \\
\text { The following investigations were normal or unremarkable: } \\
\text { 12-lead electrocardiography, two-dimensional } \\
\text { echocardiography, complete hematological screening, } \\
\text { routine biochemical profile and basic hemostasis study, } \\
\text { Echo-Doppler of the supra-aortic trunks and angio-MRI. }\end{array}$ & $\begin{array}{l}\text { Insufficient work up to grade this phenotype } \\
\text { Presence of disease } \\
\text { O- OTHER CAUSES } \\
\text { Absence of disease } \\
\text { Insufficient work up to grade this phenotype } \\
\text { Presence of disease } \\
\text { D - DISSECTION } \\
\text { Absence of disease } \\
\text { Insufficient work up to grade this phenotype } \\
\text { Presence of disease }\end{array}$ \\
\hline
\end{tabular}

Diffusion-weighted magnetic resonance imaging had a single hyperintense lesion in the internal capsule left (figure A). Periventricular and deep MRI white matter hyperintensities in FLAIR (Figure B and C). Echoplanar gradient-echo T2 *-weighted MRI had small hypointense lesions representing microbleeds in the pons. (Figure D)
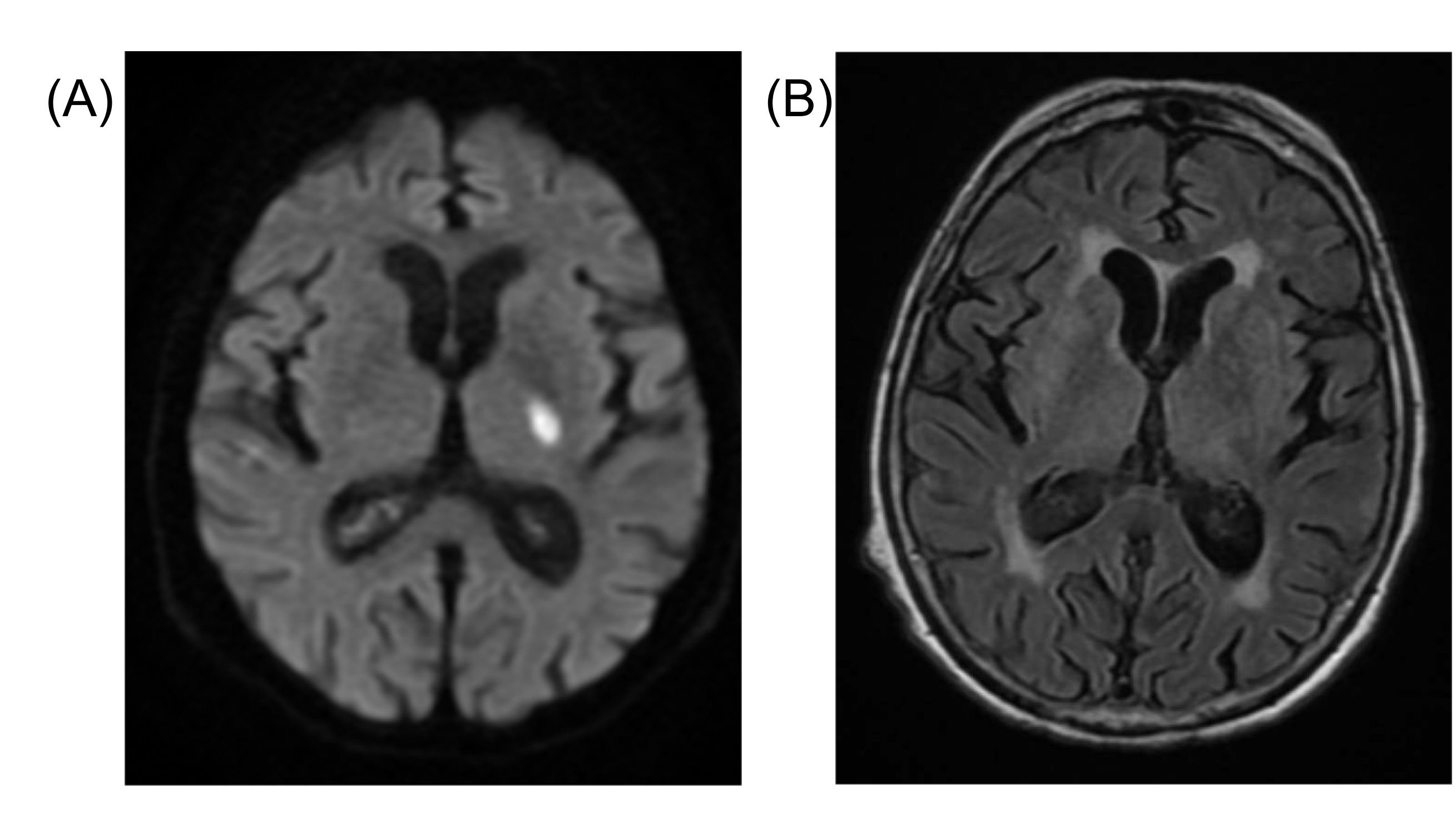

$\checkmark$ Lacunar infarction : small deep infarct $<15 \mathrm{~mm}$ on MRI (or CT) in the area corresponding to symptoms

One or several small deep older infarct of the lacunar type in other territories

$\checkmark$ Severe (confluent-Fazekas III) leukoaraiosis on MRI (and/or CT)

$\checkmark$ Microbleeds visible on T2*-weighted MRI

Severe dilatation of the perivascular spaces on T2*-weighted MRI Clinical syndrome suggestive of deep branch artery stroke without ischemic lesion in the appropriate area seen on MRI or CT [Main clinical syndrome suggesting a deep branch artery- lacunar stroke : pure motor hemiparesis, pure hemi sensory loss, Hemiparesis-ataxy, Dysarthria clumsy hand syndrome, unilateral sensory-motor deficit, others: hemichorea, hemiballism, pure dysarthria, etc.)]

Repeated, recent less than 1 month- TIAs attributable to the same Reritory, as the index infart, increases the prediction of a "lacinar

infarction" from $57 \%$ in their absence to $80 \%$ in their presence

Your ASCOD coding for this patient is:

\section{A0-S1-C0-O0-D0}

Report Summary:

This patient has no documented atherosclerotic disease. He has diffuse small vessel disease as a potential cause. No cardiac source of embolism.

And no detected other cause.

He has no evidence of cerebral artery dissection.

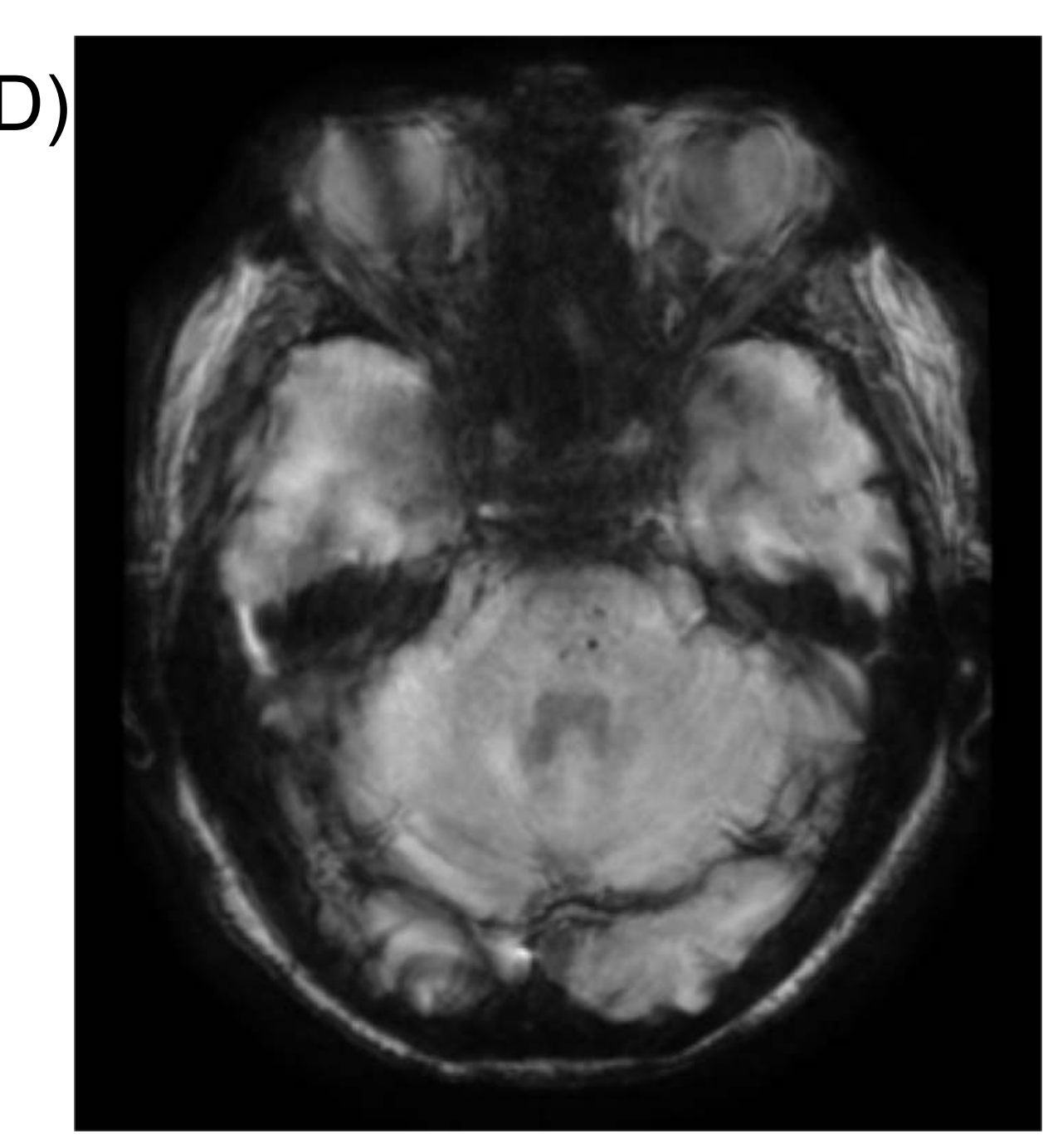

